\title{
Rare case of intraoral lipoma in lower buccal vestibule: a case report
}

\begin{abstract}
Lipoma, a benign tumor of adipose tissue is one of the most common benign neoplasms of the body. However, lipomas in the oral and maxillofacial region are rarely encountered. It accounts for 1 to $4 \%$ of benign neoplasms of mouth affecting predominantly the buccal mucosa, floor of mouth and tongue. We report a case of intraoral lipoma in buccal vestibule in which surgical excision was done under local anaesthesia.
\end{abstract}

Keywords: adipose tissue, benign tumour, fatty tumor, intraoral lipoma
Volume 5 Issue I - 2016

\section{Amit Mohan}

Department of Oral and Maxillofacial surgery, Manav Rachna

Dental College, India

Correspondence: Amit Mohan, Department of Oral and Maxillofacial surgery, Manav Rachna Dental College, India, Tel 91 97| I I 19707,Email dr.mohanamit@gmail.com

\section{Introduction}

Lipomas are the most common soft tissue mesenchymal neoplasms, with $15-20 \%$ of cases involving the head and neck region. This tumor is rarely seen in the oral cavity $(1-4 \%$ cases $) .{ }^{1}$ The most common intraoral site for lipoma is buccal mucosa, floor of mouth and tongue. The lesions are commonly seen in adults with equal distribution in males and females. ${ }^{2}$ clinically oral lipomas are seen as yellow (superficial) or pink (deep) soft, smooth nodular masses. Most of the lesions are less than $3 \mathrm{~cm}$ in size that might be sessile or pedunculated. Typically the lesion is asymptomatic unless traumatized during mastication or become noticeable due to their large size. Many patients have noticed the lesion months or years before diagnosis. Here we present a case of intraoral lipoma in a young adult male

\section{Case report}

A 20 year old male reported with the complaint of swelling in lower right buccal vestibule since 6 months. Patient first noted a small soft swelling in the mouth 6 month back which gradually increased to the present size. There was no pain and discharge noted. There was no history of rupture and reappearance. Patient was otherwise medically fit and healthy. On examination an oval shaped sessile swelling was noted in right lower buccal vestibule extending from 2 nd premolar region to mesial side of 2 nd molar region (Figure 1). The adjacent teeth were non-carious and vital. The overlying mucosa was apparently normal with slight yellowish discoloration. There was no active discharge noted. On palpation the swelling was non-tender, mobile and slippery in nature, non-reducible and not attached to superficial and deep tissue. A differential diagnosis of lipoma, epidermoid, mucocele, and was fibroma made. Radiograph examination was done with panoramic radiograph, which showed no relevant associated features. On aspiration, there was no fluid evacuated. The lesion was surgically excised under local anaesthesia. The gross specimen was non-capsulated, soft and yellowish in appearance (Figure 2). The specimen was sent for histological examination and the diagnosis of lipoma was confirmed. Patient was advised for a regular follow-up.

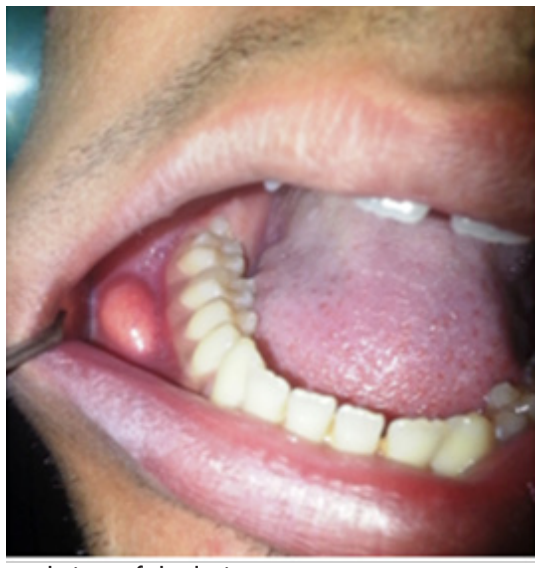

Figure I Intraoral view of the lesion.

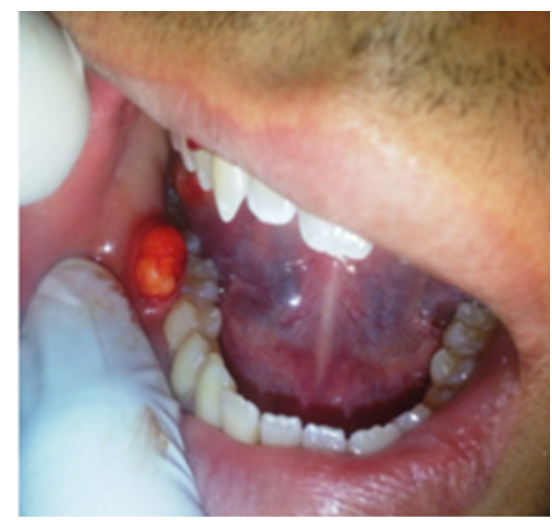

Figure 2 Gross specimen after excision.

\section{Discussion}

The lipomas occur most often in patients older than 40 years; however, in our case the lesion was seen in young adult. Since, the buccal mucosa is the region where there is abundant fatty tissue, it is 
reported to be the most common location of lipomas which occur in the oral cavity, followed by tongue and hard palate, which show very low occurrences of lipomas because they have lesser fatty tissues. ${ }^{3}$ In our case, the lesion was present in lower buccal sulcus, which is not so common intraoral site for lipoma. Clinically, oral lipomas generally present as mobile, painless sub mucosal nodules, with yellowish tinge, as observed in our cases. The diagnosis was partly based on clinical examination of the lesion as the slippery nature of the mass and yellowish tinge were highly indicative of lipoma. Although, the final diagnosis could be made by the typical nature of the gross specimen; however, the microscopic examination, which remains the gold standard in the diagnosis, was also done to confirm the findings. Lipomas are not very different in microscopic appearance from the surrounding fat. Like fat, they are composed of mature fat cells, but the cells vary slightly in size and shape and are somewhat larger, measuring up to $200 \mathrm{~mm}$ in diameter. The treatment of choice for oral lipomas is simple surgical excision. There are only exceptional chances of recurrence. Although the growth of oral lipomas is usually limited, they can reach great dimensions, interfering with speech and mastication and reinforcing the need for excision; ${ }^{4}$ however, in our case the lesion was small in size without any functional complaint, still the surgical excision was done because of the patient's concern due to the presence of an intraoral mass.

\section{Funding}

None.

\section{Acknowledgments}

None.

\section{Conflicts of interest}

Author declares that there is no conflict of interest.

\section{References}

1. Fregnani ER, Pires FR, Falzoni R, et al. Lipomas of the oral cavity: clinical findings, histological classification and proliferative activity of 46 cases. Int J Oral Maxillofac Surg. 2003;32(1):49-53.

2. Nevill B, Damm D, Allen C, et al. Oral and Maxillofacial Pathology. 3rd ed. Missouri, Saunders: USA; 2009. 523-524 p.

3. Lucas RB. Pathology of Tumors of the Oral Tissues. 4th ed. London, Churchill-Livingstone: UK; 1984. 176-179 p.

4. Chidzonga MM, Mahomva L, Marimo C. Gigantic tongue lipoma: a case report. Med Oral Patol Oral Cir Bucal. 2006;11(5):E437-439. 